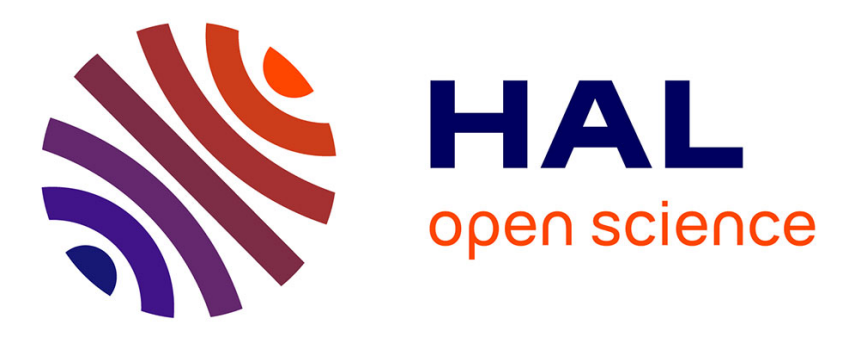

\title{
Mitochondrial biogenesis and angiogenesis in skeletal muscle of the elderly
}

Ninna Iversen, Peter Krustrup, Hans N. Rasmussen, Ulla F. Rasmussen, Bengt Saltin, Henriette Pilegaard

\section{- To cite this version:}

Ninna Iversen, Peter Krustrup, Hans N. Rasmussen, Ulla F. Rasmussen, Bengt Saltin, et al.. Mitochondrial biogenesis and angiogenesis in skeletal muscle of the elderly. Experimental Gerontology, 2011, 10.1016/j.exger.2011.03.004 . hal-00715434

\section{HAL Id: hal-00715434 \\ https://hal.science/hal-00715434}

Submitted on 7 Jul 2012

HAL is a multi-disciplinary open access archive for the deposit and dissemination of scientific research documents, whether they are published or not. The documents may come from teaching and research institutions in France or abroad, or from public or private research centers.
L'archive ouverte pluridisciplinaire $\mathbf{H A L}$, est destinée au dépôt et à la diffusion de documents scientifiques de niveau recherche, publiés ou non, émanant des établissements d'enseignement et de recherche français ou étrangers, des laboratoires publics ou privés. 


\section{Accepted Manuscript}

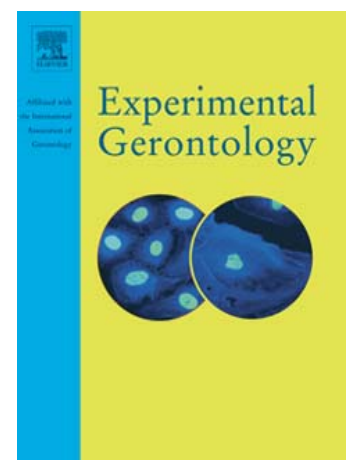

DOI:

S0531-5565(11)00088-X

Reference: $\quad$ EXG 8871

To appear in: $\quad$ Experimental Gerontology

Received date: 2 November 2010

Revised date: $\quad 15$ March 2011

Accepted date: $\quad 31$ March 2011

Please cite this article as: Iversen, Ninna, Krustrup, Peter, Rasmussen, Hans N., Rasmussen, Ulla F., Saltin, Bengt, Pilegaard, Henriette, Mitochondrial biogenesis and angiogenesis in skeletal muscle of the elderly, Experimental Gerontology (2011), doi: 10.1016/j.exger.2011.03.004

This is a PDF file of an unedited manuscript that has been accepted for publication. As a service to our customers we are providing this early version of the manuscript. The manuscript will undergo copyediting, typesetting, and review of the resulting proof before it is published in its final form. Please note that during the production process errors may be discovered which could affect the content, and all legal disclaimers that apply to the journal pertain. 


\title{
Mitochondrial biogenesis and angiogenesis in skeletal muscle of the elderly
}

\author{
NINNA IVERSEN ${ }^{1,2,3}$, PETER KRUSTRUP ${ }^{1,4}$, HANS N. RASMUSSEN ${ }^{3}$, ULLA F. \\ RASMUSSEN $^{3}$, BENGT SALTIN ${ }^{1,5}$, HENRIETTE PILEGAARD ${ }^{1,2,3}$
}

${ }^{1}$ Copenhagen Muscle Research Centre, ${ }^{2}$ Centre of Inflammation and Metabolism. ${ }^{3}$ August Krogh Building, Department of Biology, University of Copenhagen, Copenhagen, Denmark, ${ }^{4}$ Department of Exercise and Sport Sciences, Section of Human Physiology, University of Copenhagen, Copenhagen, Denmark, ${ }^{5}$ Rigshospitalet Section 7652, Copenhagen, Denmark

Key words: skeletal muscle, adaptability, lifelong training, mRNA responses, oxidative capacity

Correspondence:

Henriette Pilegaard

The August Krogh Building, Department of Biology

Universitetsparken 13

DK-2100 Copenhagen $\varnothing$, Denmark

Phone: +45 35321687

Fax: $\quad+4535321567$

E-mail: hpilegaard@bio.ku.dk 


\section{Introduction}

Ageing has been suggested to be associated with impaired mitochondrial DNA regulation and metabolic dysfunction in skeletal muscle [53]. These unfavourable changes are likely to lead to poor functional abilities in every-day life and sarcopenia [14] in elderly people as well as to enhance the risk of developing age-related metabolic diseases [34]. It has thus been suggested, that an observed age-related $\sim 40 \%$ decline in TCA cycle flux and ATP synthesis rate in skeletal muscle ultimately contributes to insulin resistance [38]. Others have however contradicted this hypothesized impaired mitochondrial function in elderly by observing well functioning skeletal muscle mitochondria in elderly human subjects with 90-95\% capacity of key oxidative enzymes relative to young subjects, except for $\beta$-oxidation which was reported to be $25 \%$ reduced [44]. Hence, it is still debated if mitochondrial function is impaired with age. Observed age-related metabolic dysfunction may either be due to a less active lifestyle in the elderly people and/or biological aging per se $[4,15,46]$.

Endurance exercise training has many beneficial effects on health in young people, including improved oxidative capacity of skeletal muscle [10]. The molecular mechanisms behind these adaptations in skeletal muscle include an increased content and/or activity of key enzymes in metabolism and angiogenesis, such as citrate synthase (CS), succinatedehydrogenase $(\mathrm{SDH})$, pyruvat-dehydrogenase $(\mathrm{PDH})$ and vascular endothelial growth factor (VEGF) [12, 16-18, 26, 29, 35]. A key mechanism behind these exercise training induced adaptations seems to be a transient transcriptional response of metabolic and angiogenic proteins to each single exercise bout orchestrated by the transcriptional co-activator peroxisome proliferator activated receptor gamma coactivator 1-alpha (PGC-1 $\alpha$ ) [40, 41]. Regularly repeated, these transient gene responses are thought to lead to an accumulation of mRNAs and ultimately proteins involved in oxidative metabolism and angiogenesis [23, 40, 54]. These transient mRNA responses seem partly to be mediated by increased phosphorylation of intracellular signalling molecules with exercise, like AMP activated protein kinase (AMPK) and P38 MAP kinase [25, 32]. The AMPK activator AICAR has been shown to upregulate PGC-1 $\alpha$ mRNA in mice skeletal muscle [21], and both AMPK and P38 has been reported to activate PGC-1 $\alpha$ by phosphorylation $[22,42]$. In addition, AMPK and P38 phosphorylation has been reported to increase in human 
$\underline{\text { skeletal muscle immediately after exercise [24]. Hence, AMPK and P38 may initiate PGC-1 } \alpha}$ mediated responses to exercise [37].

However little is known about the ability to prevent the potential age-associated decrease in oxidative enzyme capacity with exercise training, although previous observations indicate that this might be possible [47]. Thus, previous studies reported that elderly orienteer runners had $\mathrm{SDH}, \mathrm{CS}$ and 3-hydroxy-acyl-CoA-dehydrogenase (HAD) activities at the same level as endurance trained young subjects $[9,48]$. Adaptability in other parameters such as maximal oxygen consumption and muscle strength has also been reported in elderly $[19,20]$ and old people [7] and supports a general maintained ability of aged individuals to adapt to exercise training. However, it is yet not clarified whether lifelong exercise training will enhance the oxidative capacity in skeletal muscle and whether skeletal muscle of elderly people maintains the ability to adapt in metabolic and angiogenic factors to exercise training.

Therefore the aim of this study was to test the hypotheses that 1) skeletal muscles of elderly subjects have the ability to adapt to a single endurance exercise bout and 2) endurance trained elderly people have higher expression/activity of oxidative and angiogenic enzymes in skeletal muscle than untrained elderly subjects. This is evaluated by determining acute exercise induced intracellular signalling and mRNA responses as well as mitochondrial enzyme activities and metabolic and angiogenic protein contents in muscle samples from elderly endurance trained and untrained subjects. 


\section{Methods}

\subsection{Subjects}

Fourteen healthy elderly men and one healthy elderly woman, aged 67-75 years, participated in the study. Eight subjects were endurance trained (ET) and seven subjects were untrained control subjects (UT). The average age, height, weight and BMI of the ET subjects were: 71.3 years (range: 67.5-76.1), $173 \mathrm{~cm}$ (range: 159-183), $73 \mathrm{~kg}$ (range: $58.2-87.6$ ) and $24.4 \mathrm{~kg} \cdot \mathrm{m}^{-2}$ (range: 20.6-29.3), respectively. They had been engaged in endurance training (long-distance running, cross-country running, and road cycling) for the last 20-50 years with an average training frequency of 3 times/week (range: 2-6 times/week). Four of the ET subjects participated in National Master Athlete Championships in their respective events and two of them also participated in the Master Athlete World Games and Master Athletes Olympics. The average age, height, weight and BMI of the UT subjects were: $71.3 \pm 4$ years (range: $67.1-79.2$ ), $176 \mathrm{~cm}$ (range: $168-185$ ), $81.9 \mathrm{~kg}$ (range: $75.5-89.3$ ) and $26.4 \mathrm{~kg} \cdot \mathrm{m}^{-2}$ (range: $25.1-27.6$ ), respectively. They had not been exercising regularly for the last 30 years. The subjects were fully informed of the risks and discomforts associated with the experimental procedures, and all provided written consent. The study was carried out in accordance with the guidelines in the Declaration of Helsinki and was approved by the Copenhagen and Frederiksberg Ethics Committee.

\subsection{Experimental protocol}

Each participant visited the laboratory on three occasions. At the first visit, anthropometric measurements were performed, i.e. body weight, height and fat percentage (Durnin \& Womersley, 1974). The first visit was also used for familiarization to the bicycle ergometer. On the second visit, the participants performed an incremental bicycle test (Monark 125, Sweden) in order to determine the maximal oxygen uptake $\left(\mathrm{VO}_{2 \max }\right)$ and incremental exercise performance. The test was also used to determine the load eliciting $\sim 75 \%$ of individual maximal oxygen uptake $\left(\mathrm{VO}_{2 \mathrm{max}}\right)$. The incremental test consisted of 3 min of exercise at $0 \mathrm{~W}$, after which the load was adjusted upwards by $20 \mathrm{~W}$ each minute. Pulmonary gas exchange and ventilation were measured (CPX/D MedGraphics, Saint Paul, Minneapolis, US) and heart rate was recorded throughout the incremental test (Polar Electro Oy, Kempele, Finland). The $\mathrm{VO}_{2 \max }$ was defined as the highest $30 \mathrm{~s}$ mean value recorded before the subject's volitional termination of the test. 
At the third visit to the laboratory, at least 48 hours after their last training session, the subjects arrived at 9 a.m. after having consumed a light standardized breakfast consisting of cereals, bread and milk at 8 a.m. A catheter was placed in an antecubital vein and a venous blood sample was collected. In preparation for biopsies from m. vastus lateralis two incisions were made under local anesthesia (20 mg/ml lidocain) and a muscle biopsy was obtained from one of the incisions using the needle biopsy technique [1] with suction. This was followed by a continuous bicycle exercise test at $75 \% \mathrm{VO}_{2 \max }$ to exhaustion, where a muscle biopsy was obtained from the other incision 15-60 seconds after cessation of exercise. An additional muscle biopsy was taken two hours into recovery through a new incision. All biopsies were obtained with the subjects lying in the supine position on a bed standing next to the bicycle. Additional blood samples were taken from the arm vein at exhaustion and 2 hours into the recovery period.

\subsection{RNA isolation and reverse transcription}

Total RNA was isolated from $\sim 20 \mathrm{mg}$ muscle tissue by a modified guanidinium thiocyanatephenol-chloroform extraction method as previously described [5, 40].

Reverse transcription (RT) was performed using the Superscript II RNase $\mathrm{H}^{-}$system (Invitrogen, Carlsbad, CA) as previously described [13, 40]. RT products (cDNA) were diluted in sterile filtered water (Millipore, Billerica, MA) to $60 \mu \mathrm{l} / \mu \mathrm{g}$ cDNA.

\subsection{PCR}

The cDNA (mRNA) content of a given gene was determined by real time PCR using Taqman ${ }^{\circledR}$ assay as previously described [33]. Primers and TaqMan probes were designed using human database Ensembl.org and Primer Express (Applied Biosystems). Primers and TaqMan Probes with 5' FAM and 3' TAMRA labelling were purchased from TAG Copenhagen (Copenhagen, Denmark) and are listed in Table 1.

Triplicates of $10 \mu \mathrm{l}$ reaction volume were performed using Universal Mastermix (Applied Biosystem, Foster City, CA). The number of cycles until a sample reach a given fluorescence level is defined as the cycle threshold $(\mathrm{Ct})$. A serial dilution of a pooled representative sample was run on each plate and used to construct a standard curve, from which the $\mathrm{Ct}$ values of the samples were transformed to a relative mRNA amount. For each sample, the specific target 
mRNA content was normalised to GAPDH mRNA content in the given sample. The GAPDH mRNA content was not affected by training state or the acute exercise.

\subsection{Immunoblotting}

To determine the basal protein levels and exercise-induced intracellular signalling, muscle samples of $\sim 20 \mathrm{mg}$ wet weight were homogenized as previously described [26]. After centrifugating the samples for $30 \mathrm{~min}$ at $17500 \mathrm{~g}$, the supernatant was collected. Total protein content was determined by the bicinchoninic acid assay (PIERCE REAGENS, Rockford, IL). The protein amount was calculated based on a serial dilution of a BSA standard with known protein concentrations, which was run with the samples.

The samples were then diluted in sample buffer containing 0.5 M Tris Base (pH 6.8), DTT, SDS, Glycerol, Bromphenol blue to obtain $2 \mu \mathrm{g}$ total protein per $\mu 1$. Proteins were separated on $10 \%$ or 15\% Tris-HCL gels (BioRad, Stockholm, Sweden) by SDS-PAGE followed by semi-dry transfer to PVDF membranes (Millipore, Copenhagen, Denmark). Membranes were blocked for 1 hour at $4{ }^{\circ} \mathrm{C}$ (either TBST +2 or $3 \%$ skim milk or 3 or $5 \%$ BSA), incubated with primary antibodies in a solution of skim milk/BSA and TBST overnight and lastly incubated with horse radish peroxidase (HRP) conjugated secondary antibody in a solution of skim milk/BSA and TBST for 1 hour. HRP substrate was added (ECL-Plus reagent, GE Healthcare) to the membranes and band intensity of each sample was detected using Kodak Image Station E440CF (Kodak, Ballerup, Denmark). Protein content was quantified using Kodak Imaging Software (Kodak, Ballerup, Denmark). Protein content is given in arbitrary units relative to a human skeletal muscle standard sample run on each gel. Primary antibodies used were: Anti-GLUT4 (\#998101, Affinity BioReagents, Rockford, IL), anti-hexokinase II (\#28675, Santa Cruz, CA), anti-Cytocrome c (\#29573, BD, Pharmingen, CA), anti-VEGF (\#L1008, Santa Cruz, CA), anti-phospho-AMPK (\#2535S,Cell Signalling, MA), anti-AMPKa2 (Graham Hardie), anti-phospho-P38 (\#4511, Cell Signaling, MA) and anti-P38 (\#9212, Cell Signalling, MA).

\subsection{Mitochondrial preparation and enzyme activity}

The preparation method and the measurements of mitochondrial respiratory activities have previously been described in detail [43-45]. Less than 100mg muscle tissue was used and the 
preparative operations were conducted so that the measured activities could be related to tissue mass. The mitochondrial fraction contained about $40 \%$ of the tissue mitochondria.

All reported activities, except two, were measured in so-called functional assays, i.e. the enzyme was located in its normal environment, physiological substrates were used, the mitochondrial respiration was limited by the enzyme in question, and the substrate/oxygen stoichiometry was known. More detailed description of these assays is given in e.g. [43, 44].

The COX and citrate synthase assays were not functional assays. The former used nonphysiological substrates, but it was useful for comparisons. Citrate synthase was assayed by the photometric method of Shepherd and Garland after treatment of the mitochondria with Triton X$100[51]$.

All activities were measured at $25^{\circ} \mathrm{C}$ and extrapolated to $37{ }^{\circ} \mathrm{C}$ with a factor of 2.29 , corresponding to a doubling of the rates from 25 to $35^{\circ} \mathrm{C}$.

\subsection{Statistics}

All results are given as means $\pm \mathrm{SE}$. A student t-test was used to test the effect of life-long endurance exercise training on $\mathrm{VO}_{2} \max$, time to exhaustion, enzyme activity, protein content, muscle glycogen and capillarization. The hypothesis was that training increased each of these parameters and the p-values were obtained with a one-tailed test. A two way ANOVA with repeated measures was used to test the effect of training status and acute exercise on mRNA levels and on signalling. A one way ANOVA with repeated measures was used to test the effect of acute exercise on mRNA levels separately within each group. Student Newman Keuls post hoc test was used to locate differences. A significance level of $\mathrm{p}<0.05$ was chosen and a tendency is reported when $0.05 \leq \mathrm{p}<0.1$. In addition, VEGF protein and capillarization was tested for correlation using a Pearson correlation coefficient. 


\section{Results}

\subsection{Maximal whole-body oxygen uptake and endurance}

$\mathrm{VO}_{2} \max ,\left(1 \cdot \mathrm{min}^{-1} \cdot \mathrm{kg}^{-1}\right.$ bodyweight $)$ was $46 \%$ higher $(\mathrm{P}<0.05)$ in ET than in UT (Figure 1a), and when given as $1 \cdot \mathrm{min}^{-1} \sim 28 \%$ higher $(\mathrm{p}<0.05)$ in ET than in UT.

ET bicycled continuously for $86.6 \pm 7.9 \mathrm{~min}$ at $75 \% \mathrm{VO}_{2} \max$ before exhaustion, which was $35 \%$ longer $(\mathrm{p}<0.05)$ than UT (Figure $1 b)$.

\subsection{M. vastus lateralis capillarization}

The number of capillaries per fibre was $27 \%$ higher $(\mathrm{p}<0.05)$ in ET than UT, 1.77 and 1.39, respectively. Capillarization and VEGF protein content in the vastus lateralis muscle was positively correlated, with a Pearson Correlation coefficient $\sim 0.87$.

\subsection{Mitochondrial enzyme activities}

Mitochondrial protein concentration relative to muscle weight was $19 \%$ higher $(\mathrm{p}<0.05)$ in ET than in UT (Figure 2a).

PDH activity and $\beta$-oxidation were $\sim 43 \%$ and $42 \%$ higher $(\mathrm{p}<0.05)$, respectively, in ET than UT (Figure 2b-c).

Furthermore CS, SDH and $\alpha$-KG-dehydrogenase activities were 28, 36 and 54\% higher $(\mathrm{p}<0.05)$ in ET than in UT, respectively (Figure 3a-c).

ATP synthase activity and NADH-oxidase activity (reflecting the respiratory chain activity) were $46 \%$ and $35 \%$ higher $(\mathrm{p}<0.05)$ in ET than UT, respectively, while COX activity tended to be $23 \%$ higher $(0.05 \leq \mathrm{p}<0.1)$ in ET than UT (Figure $3 \mathrm{~d}-\mathrm{f})$.

\subsection{Protein expression}

Cyt c, GLUT 4 and HKII protein content was not significantly different between the groups, but the HKII protein level appeared $\sim 45 \%$ higher $(\mathrm{p}>0.1$ ) in ET than in UT (Figure 4). VEGF protein content was $\sim 230 \%$ higher $(\mathrm{p}<0.05)$ in ET than in UT (Figure 5).

\subsection{Muscle glycogen content}


Resting muscle glycogen was $447 \pm 49 \mathrm{mmol} / \mathrm{kg}$ in ET and $429 \pm 19 \mathrm{mmol} / \mathrm{kg}$ in UT and the absolute glycogen utilization during exercise was $229 \mathrm{mmol} / \mathrm{kg}$ and $172 \mathrm{mmol} / \mathrm{kg}$, respectively, with no significant difference between the groups. However, glycogen utilization/KJ work was $42 \%$ lower $(\mathrm{p}<0.05)$ in ET than in UT.

\section{6 mRNA expression}

Relative to Pre the PGC- $1 \alpha$ mRNA content increased $(\mathrm{p}<0.05) \sim 11$ fold in UT and 5 fold in ET two hours after the acute exercise bout (Figure 6a).

Exercise did not affect the HKII mRNA content significantly in any of the groups when tested with a two way or one way ANOVA. The HKII mRNA content in UT, however, tended to be $\sim 4$ fold higher $(0.05 \leq \mathrm{p}<0.1)$ in UT than ET immediately after the exercise bout and $2 \mathrm{~h}$ into recovery, when tested by a paired t-test (Figure $6 \mathrm{~b}$ ).

VEGF mRNA increased $(\mathrm{p}<0.05) \sim 4$ fold in UT immediately after the cycling bout and remained elevated $2 \mathrm{~h}$ into recovery, while there were no changes in the VEGF mRNA content with exercise in the ET group (Figure 6c).

A tendency to an overall difference $(0.05 \leq \mathrm{p}<0.1)$ in TFAM mRNA between the ET and UT group was present (Figure 6d). The UT group had an apparent increase ( $>0.1$ ) in TFAM mRNA content after the cycling bout.

\subsection{Intracellular signalling}

AMPK phosphorylation increased $(\mathrm{p}<0.05) 4.6$ and 2.5 fold in UT and ET, respectively, immediately after the exercise bout (Figure 7a), while P38 phosphorylation increased 3-4 fold in both groups after the exercise bout (Figure 7b). 


\section{Discussion}

The main findings of the present study are that endurance trained elderly subjects had higher oxidative enzyme activities and higher capillarization than untrained elderly subjects indicating an improved oxidative capacity and maintained mitochondrial function with lifelong endurance exercise training. Furthermore, untrained elderly subjects had marked exercise-induced AMPK and P38 phosphorylation as well as mRNA responses of PGC-1 $\alpha$ and VEGF, implying that skeletal muscle of elderly subjects maintains the ability to adapt and induce mitochondrial biogenesis and angiogenesis.

The present observation that skeletal muscle $\beta$-oxidation, PDH, CS, SDH, $\alpha-\mathrm{KG}-\mathrm{DH}$, NADH-oxidase and ATPase activities as well as VEGF protein content and capillarization were higher in the elderly endurance trained than in the untrained subjects is in accordance with well known endurance training induced effects in young subjects $[3,10,17,18,31,50]$. The higher enzyme activities can partly be explained by the higher mitochondrial protein content $(\sim 19 \%)$ in the endurance trained subjects, implying increased mitochondrial biogenesis in skeletal muscle of this group. The lack of a corresponding difference in Cyt c protein content is surprising, but may be related to the sensitivity of western blotting relative to enzyme activity assays combined with potential small changes in Cyt $\mathrm{c}$ protein content with endurance training as previously reported in mice [31]. In addition, the $\sim 40 \%$ higher oxidative enzyme activities and the $27 \%$ higher capillarization in the elderly endurance trained than untrained subjects, in the present study, are the same degree of improvements previously reported in young individuals [12, 27, 29] suggesting that the trainability of oxidative enzymes and capillarization in skeletal muscle is similar in elderly and young subjects. This indicates that elderly subjects who have been

physically active throughout life maintain skeletal muscle metabolic adaptations which are likely to delay or prevent the development of metabolically related diseases as well as maintaining the functional abilities in daily activities.

In contrast to previously reported mitochondrial dysfunction in elderly $[28,39,53]$, the present findings are in line with previous studies showing that mitochondria from skeletal muscle of elderly subjects are well functioning $[44,47]$. The finding that both the endurance trained and untrained elderly subjects in the present study had $\sim 2$ fold lower $\alpha \mathrm{KG}-\mathrm{DH} / \mathrm{CS}$ activity ratio than previously observed in young subjects [2], is apparently due to a higher CS activity rather than a 
lower $\alpha$ KG-DH in the elderly subjects than the young [2]. It may be speculated that this upregulation of CS activity is caused by an increased requirement of biosynthesis of triglycerides from citrate in elderly subjects for a yet unknown reason. A potential impairment of mitochondrial function in elderly and old subjects may be related to their training status, as the elderly [44] and old [47] subjects with well functioning mitochondria in previous studies were endurance trained at different levels, while the elderly with impaired mitochondrial function were sedentary [39]. In addition, it is likely that mitochondrial dysfunction may be more pronounced after the age of $\sim 75$ and only slightly detectable at a younger age, as it has been suggested for the hypertrophic response to resistance exercise training [52].

The finding that the enhanced oxidative capacity in the elderly endurance trained subjects was associated with markedly longer time to exhaustion during cycling than the untrained subjects provides evidence for functional effects of the adaptations in skeletal muscle. This is further supported by additional findings from the same subjects showing that muscle glycogen utilization/KJ and the RER value during the first 10 minutes of the exercise were lower in the endurance trained than the untrained elderly subjects (Krustrup et al 2011). This glycogen sparing and higher fat oxidation in the endurance trained subjects are likely due to the improved skeletal muscle oxidative capacity shown in the present study.

The exercise induced AMPK phosphorylation as well as PGC-1 $\alpha$ and VEGF mRNA responses, and tendency to increased HKII mRNA in the untrained subjects, are in agreement with previous findings in young subjects [8, 16, 40, 41], and support that skeletal muscle of elderly subjects maintains the ability to adapt metabolically and angiogenically to exercise training. Because the two groups in the current study exercised at $75 \% \mathrm{VO}_{2} \max$, and because a previous study in young subjects has shown that the relative workload seems to determine the acute PGC-1 $\alpha$ mRNA response [36], similar acute mRNA responses were anticipated in the untrained and the endurance trained elderly subjects. The present observations of relatively lower or complete lack of exercise induced AMPK phosphorylation, PGC-1 $\alpha$, HKII and VEGF mRNA responses in the elderly endurance trained subjects may therefore indicate an age-related loss of adaptability to acute exercise, which means a possibility of an age-associated decline in the ability to further adapt to endurance training, when already trained. There may thus exist a critical age for gaining full endurance exercise induced mRNA responses, in line with the reported decrease in hypertrophic response to resistance exercise training of same relative 
intensity from the age of 60-80 [52]. The intensity dependency observed in young subjects may therefore be shifted upwards with age and therefore require a higher exercise intensity in elderly trained to obtain a given acute mRNA response in skeletal muscle. However based on the longer time to exhaustion, it seems that the relative workload determined from whole body $\mathrm{VO}_{2} \max$ does not correspond well with the relative workload based on metabolic fitness/endurance in these elderly subjects [49]. Therefore it is possible that the acute mRNA responses would be present/more marked in the endurance trained elderly subjects, if the relative workload was based on leg muscle endurance or leg muscle $\mathrm{VO}_{2}$ max instead of whole body $\mathrm{VO}_{2}$ max. The difference in mRNA responses between the two groups may be due to the different exercise induced AMPK phosphorylation, as the AMPK activator AICAR has been shown to increase the mRNA content of PGC-1 $\alpha$, VEGF and HKII in skeletal muscle [21, 30]. Furthermore the more marked exercise induced AMPK phosphorylation in UT than ET may imply a higher level of intracellular metabolic disturbance in the untrained subjects during cycling, although working at the same $\% \mathrm{VO}_{2} \underline{m a x}$ as the endurance trained. On the contrary, the similar exercise induced P38 phosphorylation response in skeletal muscle of the untrained and endurance trained subjects may be explained by the same degree of mechanical stress during cycling in the two groups, as P38 phosphorylation has been reported to be enhanced by mechanical stress $[6,11]$.

In conclusion, the observed higher skeletal muscle oxidative enzyme activities and capillarization in lifelong endurance trained elderly subjects than in untrained elderly subjects provides evidence for beneficial effects of lifelong endurance exercise training on skeletal muscle oxidative capacity, which may improve daily functional abilities and delay sarcopenia and development of metabolically related diseases. The clear exercise induced AMPK phosphorylation as well as mRNA responses of metabolically and angiogenically related proteins in the untrained elderly subjects indicate that elderly subjects maintain the ability to adapt to an acute endurance exercise bout and thus potentially to repeated bouts of exercise. Together the present findings suggest that metabolic and angiogenic adaptability is sustained in elderly subjects at least up to the age of 75 . 


\section{Acknowledgements}

The authors would like to thank the subjects for their extraordinary effort. This work was supported by grants from The Danish Medical Research Council, Denmark, The Danish Heart Association, Denmark and the Ministry of Culture, Denmark. The Copenhagen Muscle Research Centre is supported by a grant from the Capital Region of Denmark. The Centre of Inflammation and Metabolism (CIM) is supported by a grant from the Danish National Research Foundation (\# $02-512-55)$ 


\section{Reference List}

1. Bergström J. Muscle electrolytes in man. supplement 68 1962; 14:1-110

2. Blomstrand E, Radegran G, Saltin B. Maximum rate of oxygen uptake by human skeletal muscle in relation to maximal activities of enzymes in the Krebs cycle. J Physiol 1997; 501 ( Pt 2):455-460

3. Booth FW, Tseng BS, Fluck M, Carson JA. Molecular and cellular adaptation of muscle in response to physical training. Acta Physiol Scand. 1998; 162:343-350

4. Booth FW, Gordon SE, Carlson CJ, Hamilton MT. Waging war on modern chronic diseases: primary prevention through exercise biology. J Appl Physiol 2000; 88:774-787

5. Chomczynski P, Sacchi N. Single-step method of RNA isolation by acid guanidinium thiocyanate-phenolchloroform extraction. Analytical Biochemistry 1987; 162:156-159

6. D'Addario M, Arora PD, Ellen RP, McCulloch CAG. Interaction of p38 and Sp1 in a Mechanical Forceinduced, +1 Integrin-mediated Transcriptional Circuit That Regulates the Actin-binding Protein Filamin-A. J.Biol.Chem. 2002; 277:47541-47550

7. Deley G, Kervio G, Van HJ, Verges B, Grassi B, Casillas JM. Effects of a one-year exercise training program in adults over 70 years old: a study with a control group. Aging Clin Exp.Res. 2007; 19:310-315

8. Fujii N, Hayashi T, Hirshman MF, Smith JT, Habinowski SA, Kaijser L, Mu J, Ljungqvist O, Birnbaum MJ, Witters LA, Thorell A, Goodyear LJ. Exercise Induces Isoform-Specific Increase in 5'AMPActivated Protein Kinase Activity in Human Skeletal Muscle. Biochemical and Biophysical Research Communications 2000; 273:1150-1155

9. Gollnick PD, Armstrong RB, Saubert CW, Piehl K, Saltin B. Enzyme activity and fiber composition in skeletal muscle of untrained and trained men. J Appl Physiol 1972; 33:312-319

10. Gollnick PD, Saltin B. Significance of skeletal muscle oxidative enzyme enhancement with endurance training. Clin Physiol 1982; 2:1-12

11. Hanke N, Kubis HP, Scheibe RJ, Berthold-Losleben M, H++sing O, Meissner JD, Gros G. Passive mechanical forces upregulate the fast myosin heavy chain IId/x via integrin and $\mathrm{p} 38$ MAP kinase activation in a primary muscle cell culture. American Journal of Physiology - Cell Physiology 2010; 298:C910-C920

12. Henriksson and Reitman. Time course of changes in human skeletal muscle succinate dehydrogenase and cytochrome oxidase activities and maximal oxygen uptake with physical activity and inactivity. Acta Physiol Scand 1977; Jan;99(1):91-7

13. Hildebrandt AL, Neufer PD. Exercise attenuates the fasting-induced transcriptional activation of metabolic genes in skeletal muscle. Am J Physiol Endocrinol Metab 2000; 278:E1078-E1086

14. Hiona A, Leeuwenburgh $\mathrm{C}$. The role of mitochondrial DNA mutations in aging and sarcopenia: Implications for the mitochondrial vicious cycle theory of aging. Experimental Gerontology 2008; 43:24-33

15. Hipkiss AR. Mitochondrial dysfunction, proteotoxicity, and aging: causes or effects, and the possible impact of NAD+-controlled protein glycation. Adv.Clin.Chem. 2010; 50:123-150 
16. Hiscock N, Fischer CP, Pilegaard H, Pedersen BK. Vascular endothelial growth factor mRNA expression and arteriovenous balance in response to prolonged, submaximal exercise in humans. Am J Physiol Heart Circ.Physiol 2003; 285:H1759-H1763

17. Hoffner L, Nielsen JJ, Langberg H, Hellsten Y. Exercise but not prostanoids enhance levels of vascular endothelial growth factor and other proliferative agents in human skeletal muscle interstitium. J Physiol 2003; 550:217-225

18. Holloszy JO, Coyle EF. Adaptations of skeletal muscle to endurance exercise and their metabolic consequences. J Appl Physiol 1984; 56:831-838

19. Hughes VA, Fiatarone MA, Fielding RA, Ferrara CM, Elahi D, Evans WJ. Long-term effects of a highcarbohydrate diet and exercise on insulin action in older subjects with impaired glucose tolerance. Am J Clin Nutr 1995; 62:426-433

20. Hurley BF, Redmond RA, Pratley RE, Treuth MS, Rogers MA, Goldberg AP. Effects of strength training on muscle hypertrophy and muscle cell disruption in older men. Int.J Sports Med. 1995; 16:378-384

21. J++rgensen SB, Wojtaszewski JFP, Viollet B, Andreelli F, Birk JB, Hellsten Y, Schjerling P, Vaulont S, Neufer PD, Richter EA, Pilegaard H. Effects of +-AMPK knockout on exercise-induced gene activation in mouse skeletal muscle. FASEB J.

22. Jager S, Handschin C, St-Pierre J, Spiegelman BM. AMP-activated protein kinase (AMPK) action in skeletal muscle via direct phosphorylation of PGC-1alpha. Proc.Natl.Acad Sci U.S.A 2007; 104:1201712022

23. Jensen L, Pilegaard H, Neufer PD, Hellsten Y. Effect of acute exercise and exercise training on VEGF splice variants in human skeletal muscle. Am J Physiol Regul Integr Comp Physiol 2004; 287:R397-R402

24. Jorgensen SB, Treebak JT, Viollet B, Schjerling P, Vaulont S, Wojtaszewski JFP, Richter EA. Role of AMPK $\{$ alpha 2 in basal, training-, and AICAR-induced GLUT4, hexokinase II, and mitochondrial protein expression in mouse muscle. Am J Physiol Endocrinol Metab 2007; 292:E331-E339

25. Kahn BB, Alquier T, Carling D, Hardie DG. AMP-activated protein kinase: Ancient energy gauge provides clues to modern understanding of metabolism. Cell Metabolism 2005; 1:15-25

26. Kiilerich K, Birk JB, Damsgaard R, Wojtaszewski JFP, Pilegaard H. Regulation of PDH in human arm and leg muscles at rest and during intense exercise. Am J Physiol Endocrinol Metab 2008; 294:E36-E42

27. Klausen K, Andersen LB, Pelle I. Adaptive changes in work capacity, skeletal muscle capillarization and enzyme levels during training and detraining. Acta Physiol Scand. 1981; 113:9-16

28. Lanza I.R., Nair K.S. Regulation of skeletal muscle mitochondrial function: genes to proteins. Acta Physiol 2010; 199:529-547

29. LeBlanc PJ, Peters SJ, Tunstall RJ, Cameron-Smith D, Heigenhauser GJF. Effects of aerobic training on pyruvate dehydrogenase and pyruvate dehydrogenase kinase in human skeletal muscle. J Physiol $2004 ; 557: 559-570$

30. Leick L, Lyngby SS, Wojtasewski JrF, Pilegaard H. PGC-1[alpha] is required for training-induced prevention of age-associated decline in mitochondrial enzymes in mouse skeletal muscle. Experimental Gerontology In Press, Corrected Proof 
31. Leick L, Wojtaszewski JFP, Johansen ST, Kiilerich K, Comes G, Hellsten Y, Hidalgo J, Pilegaard H. PGC1 alpha\} is not mandatory for exercise- and training-induced adaptive gene responses in mouse skeletal muscle. Am J Physiol Endocrinol Metab 2008; 294:E463-E474

32. Little JP, Safdar A, Cermak N, Tarnopolsky MA, Gibala MJ. Acute endurance exercise increases the nuclear abundance of PGC-1+! in trained human skeletal muscle. American Journal of Physiology Regulatory, Integrative and Comparative Physiology 2010; 298:R912-R917

33. Lundby C, Nordsborg N, Kusuhara K, Kristensen KM, Neufer PD, Pilegaard H. Gene expression in human skeletal muscle: alternative normalization method and effect of repeated biopsies. Eur J Appl Physiol 2005; 95:351-360

34. Mathers CD, Loncar D. Projections of global mortality and burden of disease from 2002 to 2030. PLoS.Med 2006; $3: \mathrm{e} 442$

35. Nordby P, Saltin B, Helge JW. Whole-body fat oxidation determined by graded exercise and indirect calorimetry: a role for muscle oxidative capacity?

1. Scand.J Med Sci Sports 2006; 16:209-214

36. Nordsborg NB, Lundby C, Leick L, Pilegaard H. Relative Workload Determines Exercise Induced Increases in PGC-1alpha mRNA. Med.Sci.Sports Exerc. 2010;

37. Olesen J, Kiilerich K, Pilegaard H. PGC-1+1-mediated adaptations in skeletal muscle. Pfl++gers Archiv European Journal of Physiology 2010; 460:153-162

38. Petersen KF, Befroy D, Dufour S, Dziura J, Ariyan C, Rothman DL, DiPietro L, Cline GW, Shulman GI. Mitochondrial dysfunction in the elderly: possible role in insulin resistance. Science 2003; 300:1140-1142

39. Petersen KF, Befroy D, Dufour S, Dziura J, Ariyan C, Rothman DL, DiPietro L, Cline GW, Shulman GI. Mitochondrial dysfunction in the elderly: possible role in insulin resistance. Science 2003; 300:1140-1142

40. Pilegaard H, Ordway GA, Saltin B, Neufer PD. Transcriptional regulation of gene expression in human skeletal muscle during recovery from exercise. Am J Physiol Endocrinol Metab 2000; 279:E806E814

41. Pilegaard H, Saltin B, Neufer PD. Exercise induces transient transcriptional activation of the PGC-1alpha gene in human skeletal muscle. J Physiol 2003; 546:851-858

42. Puigserver P, Rhee J, Lin J, Wu Z, Yoon JC, Zhang CY, Krauss S, Mootha VK, Lowell BB, Spiegelman BM. Cytokine Stimulation of Energy Expenditure through p38 MAP Kinase Activation of PPAR[gamma] Coactivator-1. Molecular Cell 2001; 8:971-982

43. Rasmussen HN, Andersen AJ, Rasmussen UF. Optimization of Preparation of Mitochondria from 25-100 mg Skeletal Muscle. Analytical Biochemistry 1997; 252:153-159

44. Rasmussen UF, Krustrup P, Kj $\mu \mathrm{r}$ M, Rasmussen HN. Experimental evidence against the mitochondrial theory of aging A study of isolated human skeletal muscle mitochondria. Experimental Gerontology 2003; 38:877-886

45. Rasmussen UF, Rasmussen HN. Human quadricepts muscle mitochondria: A functional characterization. Molecular and Cellular Biochemistry 2000; 208:37-44

46. Rifkind BM. Diet, Plasma Cholesterol and Coronary Heart Disease. J.Nutr. 1986; 116:1578-1580 
47. Safdar A, Hamadeh MJ, Kaczor JJ, Raha S, Debeer J, Tarnopolsky MA. Aberrant mitochondrial homeostasis in the skeletal muscle of sedentary older adults. PLoS.ONE. 2010; 5:e10778

48. Saltin B. The ageing endurance athlete. In: AnonymousBenchmark Press, Inc. 1986: 59-80

49. Saltin B, Pilegaard H. [Metabolic fitness: physical activity and health]. Ugeskr.Laeger 2002; 164:2156-2162

50. Schantz P, Henriksson J, Jansson E. Adaptation of human skeletal muscle to endurance training of long duration. Clin.Physiol 1983; 3:141-151

51. Shepherd D, GARLAND PB. ATP controlled acetoacetate and citrate synthesis by rat liver mitochondria oxidising palmitoyl-carnitine, and the inhibition of citrate synthase by ATP. Biochemical and Biophysical Research Communications 1966; 22:89-93

52. Slivka D, Raue U, Hollon C, Minchev K, Trappe S. Single muscle fiber adaptations to resistance training in old (>80 yr) men: evidence for limited skeletal muscle plasticity. Am J Physiol Regul Integr Comp Physiol 2008; 295:R273-R280

53. Squier TC. Oxidative stress and protein aggregation during biological aging. Experimental Gerontology $2001 ; 36: 1539-1550$

54. Williams R.S and Neufer P.D. Regulation of gene expression in skeletal muscle by contractile activity. In: Anonymous1996 
Table and figure legends

\section{Table 1.}

Forward Primers (FP), Reverse Primers (RP) and TaqMan Probes sequences used for real time PCR to detect peroxisome proliferator-activated receptor gamma coactivator 1-alpha (PGC-1 $\alpha$ ), hexokinase II (HKII), vascular endothelial growth factor (VEGF) and Transcription factor A, mitochondrial (TFAM) mRNA.

\section{Figure 1.}

Maximal oxygen uptake, $\mathrm{VO}_{2} \max \left(\mathrm{ml} \cdot \mathrm{min}^{-1} \cdot \mathrm{kg}^{-1}\right)$ and time to exhaustion (min) at $75 \% \mathrm{VO}_{2} \max$ in endurance trained (ET; $n=8)$ and untrained (UT; $n=7$ ) elderly subjects. Values are mean \pm SE. a: significantly different from UT, $\mathrm{p}<0.05$

\section{Figure 2.}

a) Mitochondrial protein concentration ( $\mathrm{mg} \cdot \mathrm{g}^{-1}$ muscle), b) $\beta$-oxidation and c) pyruvate dehydrogenase (PDH) activity in isolated mitochondria obtained from vastus lateralis muscle biopsies from endurance trained (ET; $n=8)$ and untrained (UT; $n=7$ ) elderly subjects at rest. Values are mean \pm SE. $\not$ : significantly different from UT, $p<0.05$.

\section{Figure 3.}

a) Citrate synthase (CS), b) succinate dehydrogenase (SDH), c) $\alpha$-ketoglutarat-dehydrogenase $(\alpha-$ KG-DH), d) NADH oxidase, e) cytochrome c oxidase (COX) and f) ATP synthase activity in isolated mitochondria obtained from vastus lateralis muscle biopsies from endurance trained $(\mathrm{ET} ; \mathrm{n}=8)$ and untrained $(\mathrm{UT} ; \mathrm{n}=7$ ) elderly subjects at rest. Values are mean $\pm \mathrm{SE}$. $\mathrm{x}$ : significantly different from UT, $p<0.05$, \#: Tends to be significantly different from UT, $0.05 \leq \mathrm{p}<0.1$.

\section{Figure 4.}

a) Glucose transporter type 4 (GLUT4), b) hexokinase II (HKII) and c) cytocrome c (Cyt c) protein content in vastus lateralis muscle biopsies from endurance trained $(E T ; n=7)$ and untrained (UT; $n=6)$ elderly subjects at rest. Values are mean \pm SE.

\section{Figure 5.}

Vascular endothelial growth factor (VEGF) protein content in vastus lateralis muscle biopsies from endurance trained (ET; $n=5)$ and untrained $(\mathrm{UT} ; \mathrm{n}=5)$ elderly subjects at rest. Values are mean \pm SE. : : significantly different from UT, $p<0.05$.

\section{Figure 6.}

a) mRNA content of peroxisome proliferator activated receptor gamma coactivator 1-alpha $(\mathrm{PGC}-1 \alpha), b)$ hexokinase II (HKII), c) vascular endothelial growth factor (VEGF) and d) transcription factor A, mitochondrial (TFAM) in vastus lateralis muscle biopsies obtained from endurance trained (ET; $n=7)$ and untrained $(\mathrm{UT} ; \mathrm{n}=6)$ elderly subjects before (Pre) and immediately after $\left(0^{\prime}\right)$ an acute exercise bout and at $2 \mathrm{~h}$ of recovery $(2 \mathrm{~h})$. The target mRNA was normalized to GAPDH mRNA content. Values are mean \pm SE. *: significantly different from Pre, $p<0.05$, $\ddagger$ tendency to overall difference between the two groups, $0.05 \leq \mathrm{p}<0.1$. 


\section{Figure 7.}

a) mRNA content in skeletal muscle of phosphorylated AMP activated protein kinase (p-AMPK) and b) phosphorylated P38 MAP kinase (p-P38) in lifelong endurance trained $(n=7)$ and untrained (UT) $(\mathrm{n}=6)$ elderly subjects before (Pre) and immediately after (0h) an acute exercise bout. The target protein was normalized to total protein content. Values are mean \pm SE. *: significantly different from Pre, $\mathrm{p}<0.05, \S$ : Tends to be significantly different from Pre, $0.05 \leq \mathrm{p}<0.1$. 
Table 1. Primer and TaqMan probe sequences used for real time PCR

\begin{tabular}{|l|ll|}
\hline \multirow{3}{*}{ PGC-1 $\alpha$} & FP & 5'CAAGCCAAACCAACAACTTTATCTCT3' \\
& RP & 5'CACACTTAAGGTGCGTTCAATAGTC3' \\
& Probe & 5'AGTCACCAAATGACCCCAAGGGTTCC3' \\
\hline \multirow{3}{*}{ HKII } & FP & 5' TTGTCCGTAACATTCTCATCGATT 3' \\
& RP & 5' 'TGTCTTGAGCCGCTCTGAGAT 3' \\
& Probe & 5' ACCAAGCGTGGACTGCTCTTCCGA 3' \\
\hline \multirow{3}{*}{ VEGF } & FP & 5' CTTGCTGCTCTACCTCCACCAT 3' \\
& RP & 5' ATGATTCTGCCCTCCTCCTTCT 3' \\
& Probe & 5' AAGTGGTCCCAGGCTGCACCCA 3' \\
\hline \multirow{2}{*}{ TFAM } & FP & 5' AGATTCCAAGAAGCTAAGGGTGATT 3' \\
& RP & 5' TTTCAGAGTCAGACAGATTTTTCCA 3' \\
& Probe & 5' CCGCAGGAAAAGCTGAAGACTGTAAAGGA 3' \\
\hline
\end{tabular}


Figure 1

a)

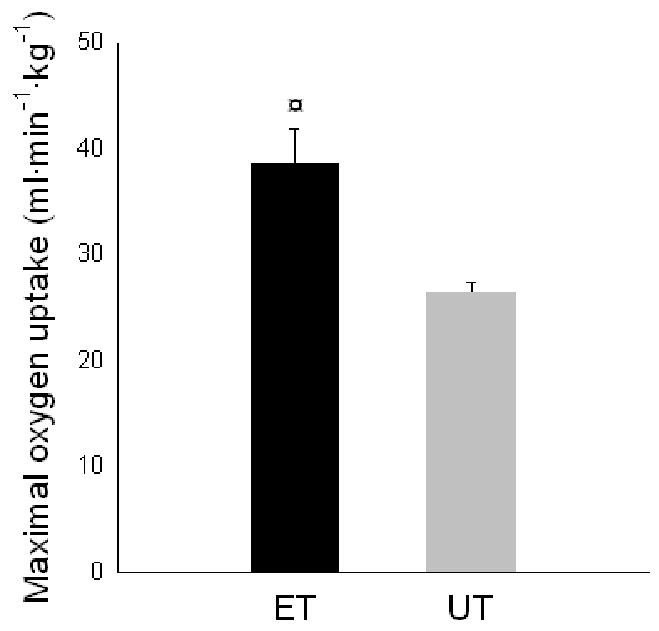

b)

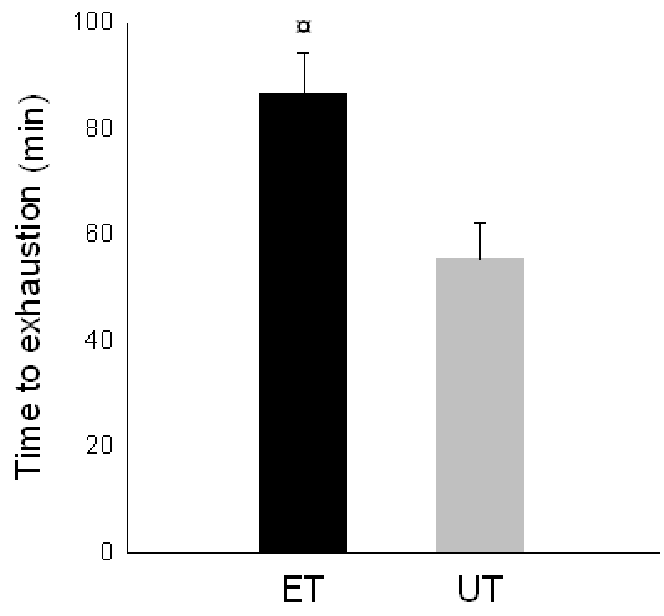


Figure 2
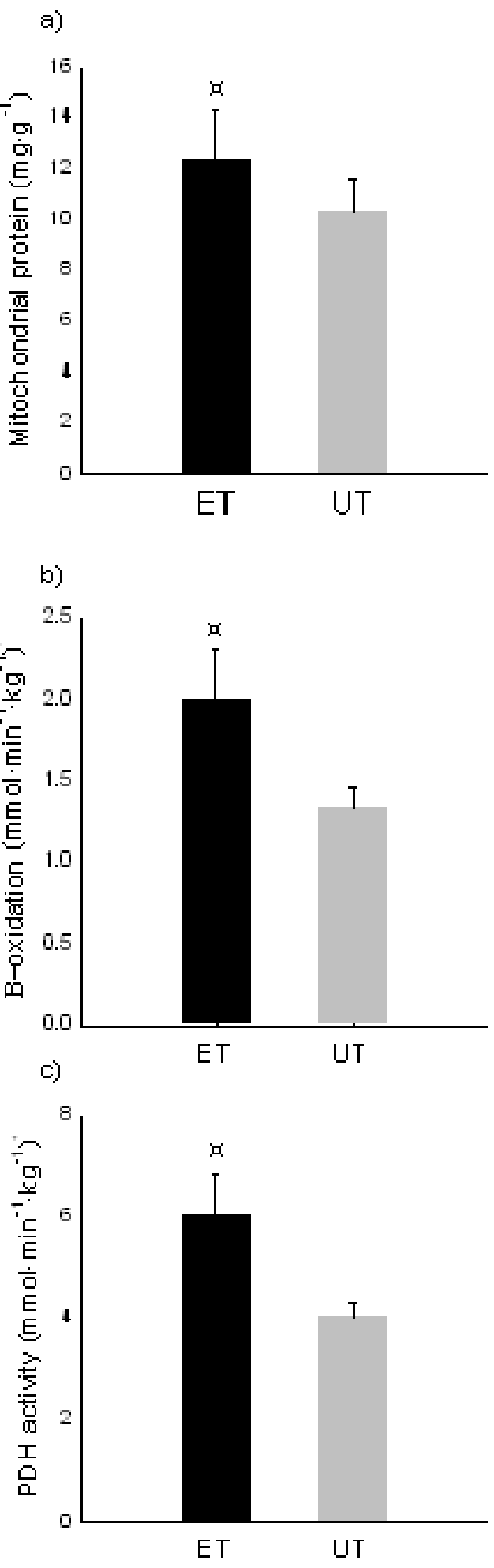
Figure 3
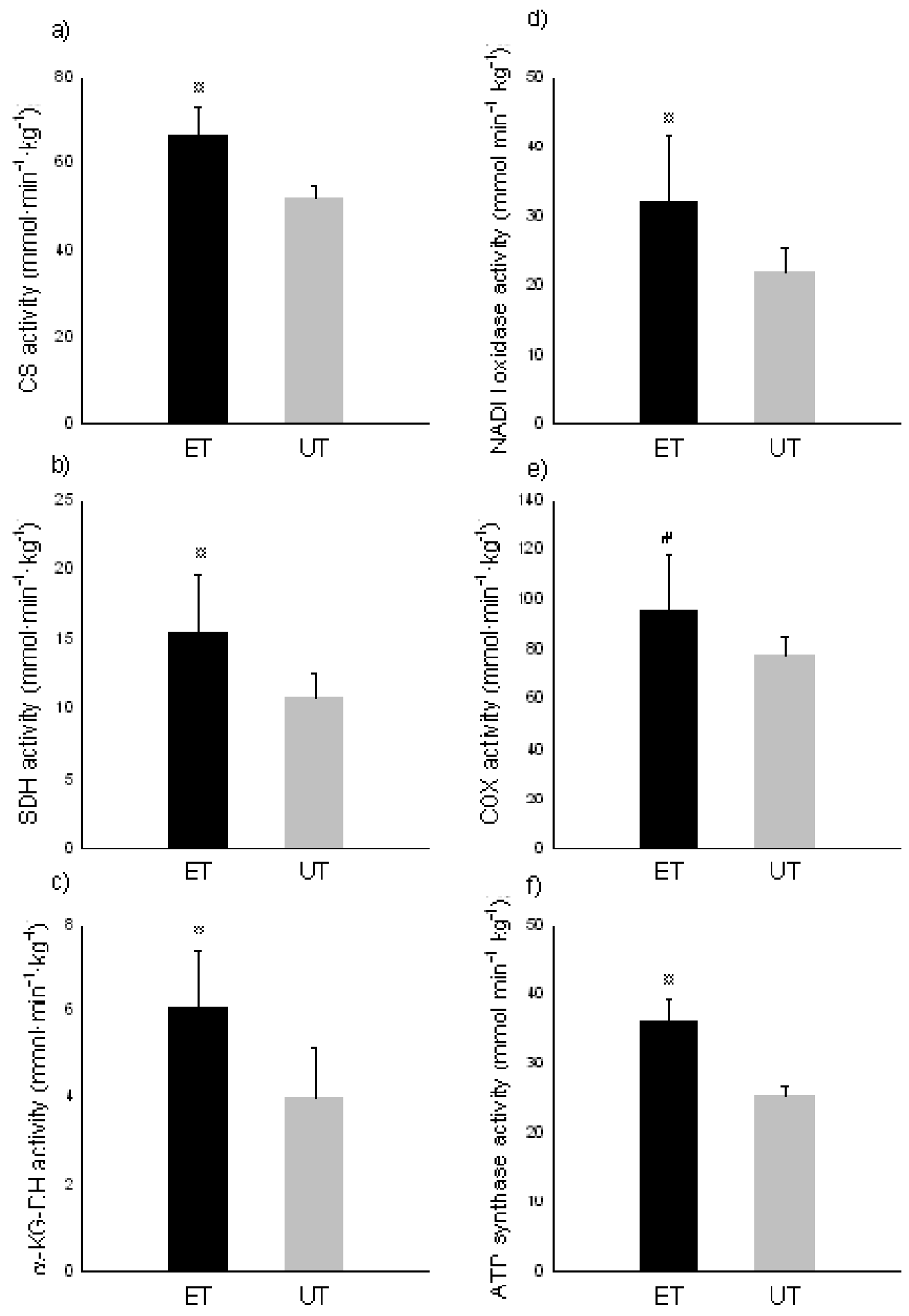
Figure 4
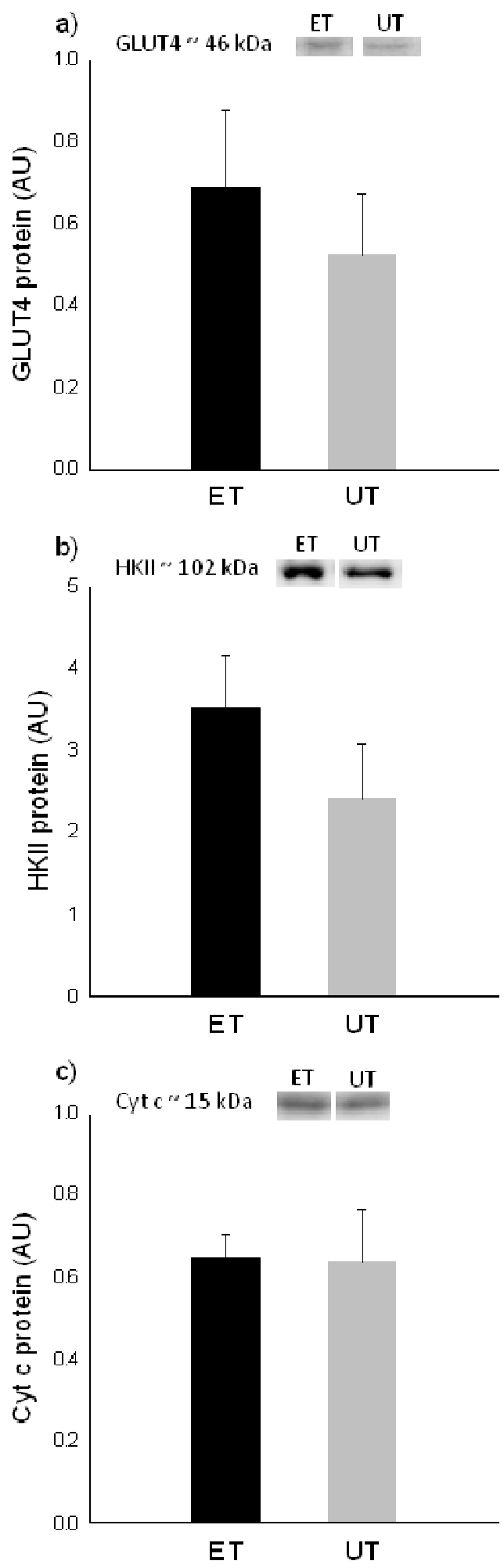
Figure 5
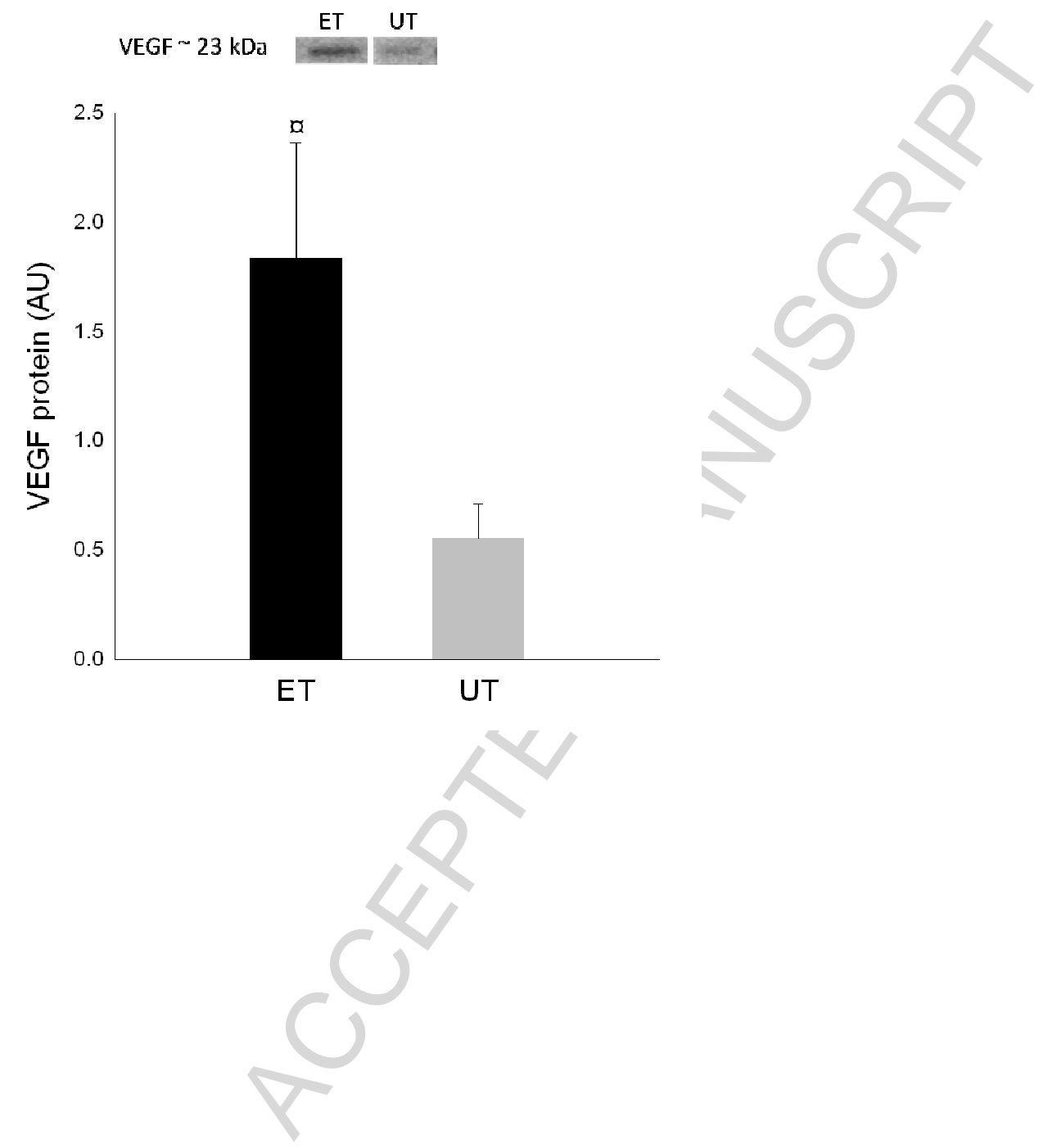
Figure 6

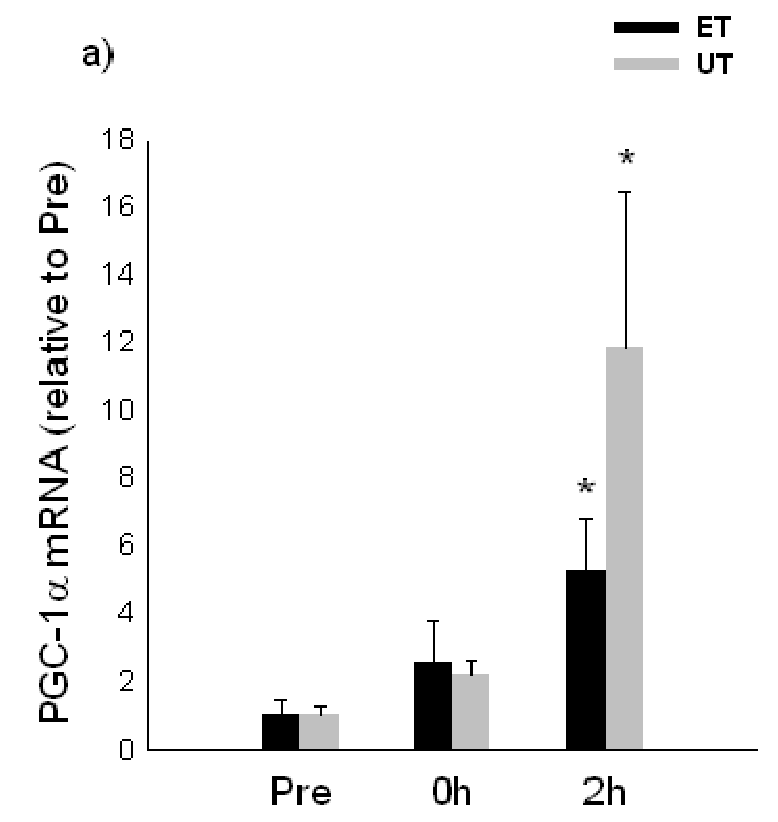

b)

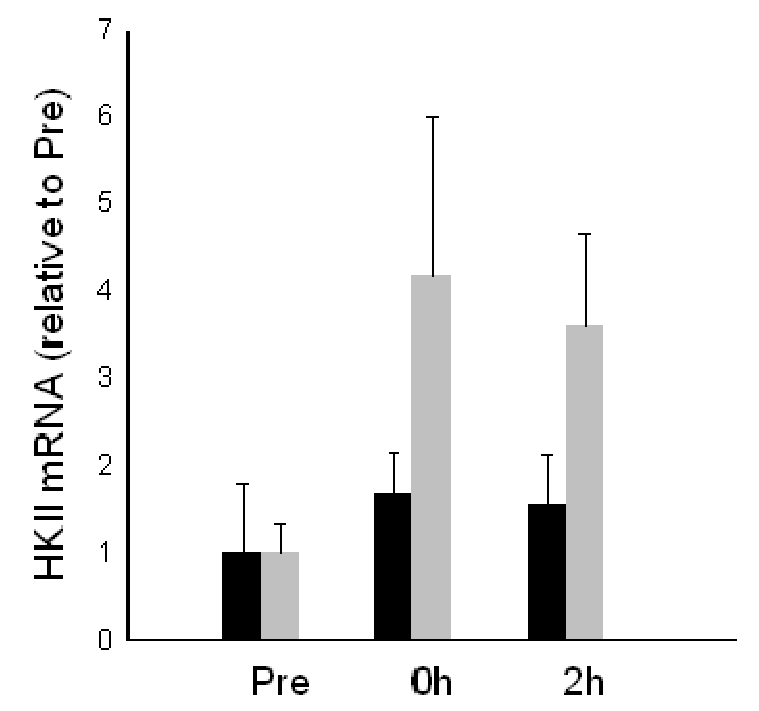

c)

d)
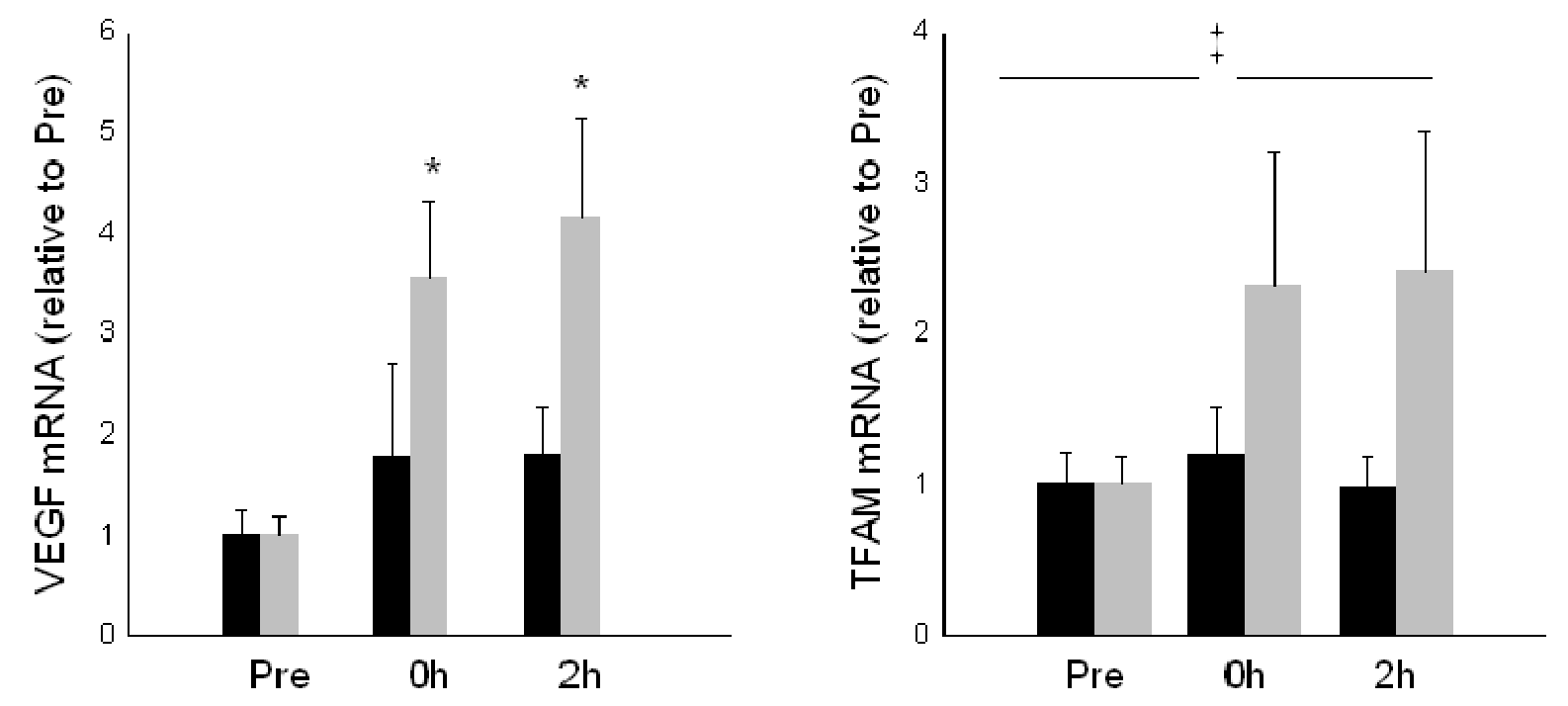
Figure 7
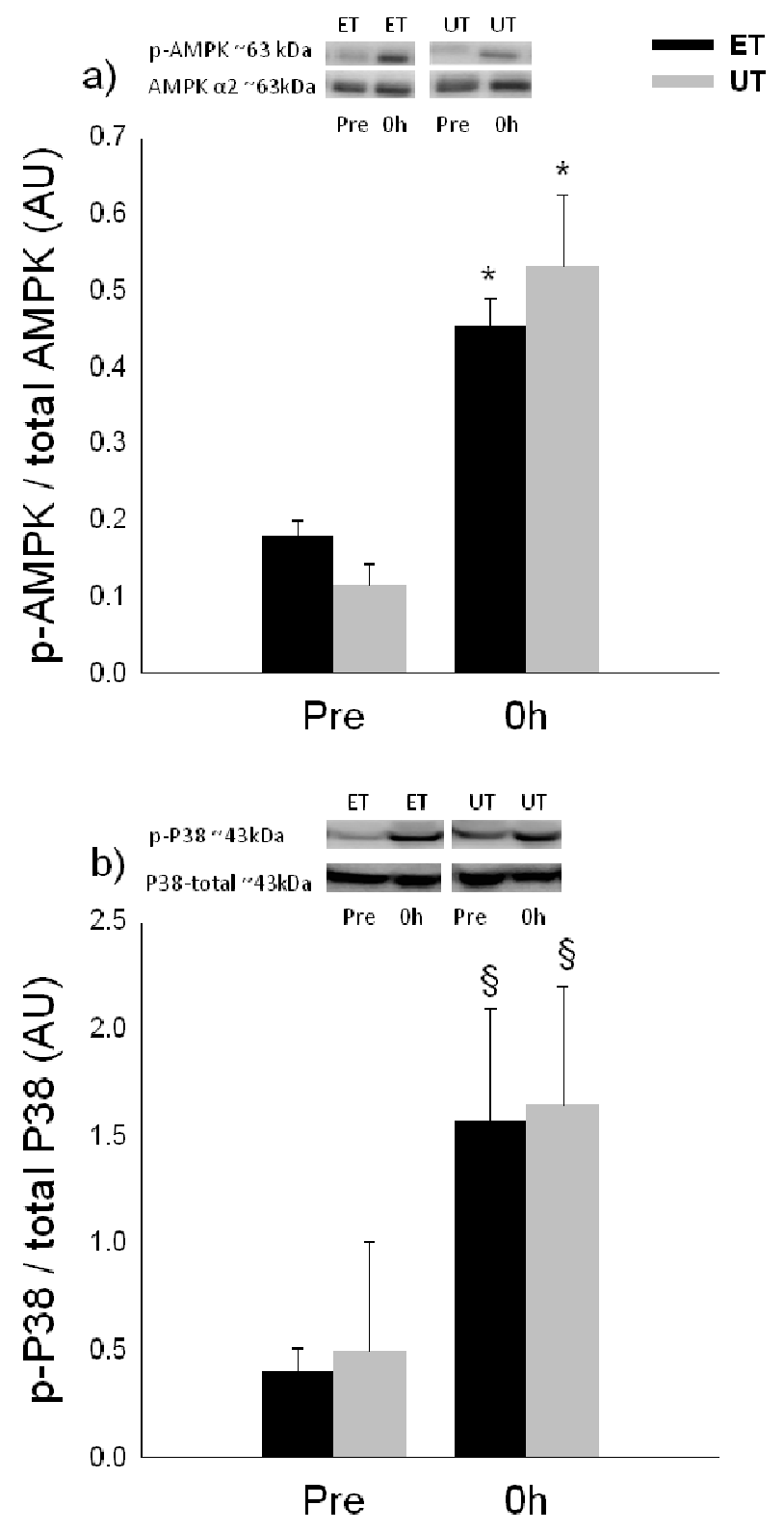


\section{Research highlights}

The main findings of the present study are that endurance trained elderly subjects had higher oxidative enzyme activities and higher capillarization than untrained elderly subjects indicating an improved oxidative capacity and maintained mitochondrial function. Furthermore, untrained elderly subjects had marked exercise-induced mRNA responses of PGC- $1 \alpha$ and VEGF, implying that skeletal muscle of elderly subjects maintains the ability to induce mitochondrial biogenesis and angiogenesis. 